ISSN: 0213-2060

DOI: http://dx.doi.org/10.14201/shhme20153397117

\title{
HISTORIOGRAFÍA Y PODER AL FINAL DE LA EDAD MEDIA: EN TORNO AL OFICIO DE CRONISTA
}

\author{
Historiography and Power in the Late Middle Ages: \\ Regarding the Chronicler's Profession
}

\author{
Francisco BAUTISTA PÉREZ \\ Depto. de Literatura Española e Hispanoamericana. Facultad de Filología. Universidad de Salamanca. Plaza de \\ Anaya, s/n.E-37008 SALAMANCA. C. e.: francisco.bautista@usal.es
}

Recibido: 2015-04-06

Revisado: 2015-07-22

Aceptado: 2015-09-28

RESUMEN: Este trabajo pretende explorar la emergencia de la figura del cronista oficial en Castilla, las razones de la creación de este cargo, y los debates y problemas que se suscitaron en torno a él en el siglo XV. El cargo de cronista oficial, ligado a la creciente burocratización de la monarquía, parece apuntar también a un deseo de control de la escritura histórica, así como al intento de autorizar solamente la versión emanada desde las instancias del poder. Pero muy pronto los mismos cronistas oficiales reclamaron un espacio propio, tanto intelectual como político, lo que ocasionó en ocasiones su destitución, y el mismo cargo de cronista generó un agudo debate explicitado por vez primera por Fernán Pérez de Guzmán en el prólogo a las Generaciones y semblanzas (c 1460). Este trabajo se propone investigar estas tensiones, llegando hasta la época de los Reyes Católicos.

Palabras clave: Letrados; Oficios burocráticos; Teoría historiográfica; Ideología; Retórica.

ABSTRACT: This article aims to explore the beginnings of official chronicler in Castile, the reasons for the creation of this post, and the intellectual debates and problems that arose in relation to it during the $15^{\text {th }}$ Century. The post of official chronicler, linked to the growing bureaucratization of monarchy, seems to obey to the demands of controlling the writing of 
FRANCISCO BAUTISTA PÉREZ

HISTORIOGRAFÍA Y PODER AL FINAL DE LA EDAD MEDIA: EN TORNO

AL OFICIO DE CRONISTA

history, and it is as well an attempt to authorize the vision of the past created under the auspices of power. Nevertheless, chronicles searched for their own autonomy, either intellectual or political, which sometimes gave birth to tensions and in the end it could provoke their destitution. On the other hand, the very notion of an official chronicle was seen by some individuals as a menace for the task of writing the past, as was voiced by Fernán Pérez de Guzmán in the prologue to his Generaciones y semblanzas (c. 1460). This article is devoted to these tensions, reaching to the epoch of the Catholic Monarchs.

Keywords: Intellectuals; Bureaucratic Offices; Theory of Historiography; Ideology; Rhetoric.

SUMARIO: 1 Referencias bibliográficas.

Obra literaria, registro del pasado, fuente de modelos y ejemplos, o arma política, la potencialidad de la historiografía durante el siglo xv la convirtió en uno de los géneros centrales de este periodo. La ampliación del público, la renovación de sus bases textuales, con la recuperación de los historiadores clásicos, sobre todo romanos, y su relevancia cultural dieron lugar además a una extraordinaria diversificación en cuanto a formas, registros y plasmaciones materiales. Robert B. Tate, uno de los mejores conocedores de este periodo, lo señaló con perspicacia: «En la historiografía medieval de la Península Ibérica no hay ningún siglo que pueda competir con el xV en la variedad de formas y en las diversas maneras de abordar temas históricos [...] nunca antes había atraído tanto la atención de nobles, clero y clase letrada la historiografía en latín y lengua vernácula» ${ }^{1}$. Ahora bien, cabe señalar además que tal florecimiento y diversidad ocurre principalmente en el terreno de la historia sobre el pasado reciente, que es ahora no solo dominio de las crónicas regias, sino también de memorias, biografías, retratos o misceláneas que agrupan documentos y en ocasiones fragmentos narrativos o poéticos. Se diría, entonces, que tal ampliación de la escritura histórica se encuentra estrechamente vinculada a una transformación en la valoración del presente y de su memoria por diversos individuos y grupos sociales a lo largo del siglo xv. Si la redacción de obras de historia política queda circunscrita en los siglos anteriores al poder regio o a su entorno, ahora encontraremos nuevas instancias de producción, nuevos sujetos que ocupan el centro del relato y, en general, una nueva articulación de la información, cuyo horizonte no es ya exclusivamente el de las crónicas reales.

En este contexto, puede hablarse también de una redefinición de las relaciones entre poder y escritura histórica. La función de los historiadores no es ya solo colocar el pasado al servicio del presente, como puede suceder en el ciclo cronístico elaborado

1 TATE, Robert B. Ensayos sobre la historiografía peninsular del siglo XV. Madrid: Gredos, 1970, p. 281. Véase también García, Michel. «La crónica castellana en el siglo XV». En Lucía Megías, José Manuel; Gracia Alonso, Paloma y Martín Daza, Carmen (eds.). Actas del II Congreso Internacional de la Asociación Hispánica de Literatura Medieval. Alcalá de Henares: Universidad de Alcalá, 1992, vol. I, pp. 53-70; y CuART Moner, Baltasar. «La larga marcha hacia las historias de España en el siglo XVI». En GArCía CÁrcel, Ricardo (coord.). La construcción de las historias de España. Madrid: Marcial Pons, 2004, pp. 45-126 y 383-386. 
FRANCISCO BAUTISTA PÉREZ

HISTORIOGRAFÍA Y PODER AL FINAL DE LA EDAD MEDIA: EN TORNO

AL OFICIO DE CRONISTA

bajo Alfonso XI, o legitimar una nueva dinastía, como en las crónicas de Pero López de Ayala, sino exponer las propias tareas de gobierno, las embajadas, negociaciones y acuerdos a través de los que se manifiesta el ejercicio del poder, de modo que la historiografía se transforma de manera cada vez más acusada en un análisis político. Quizá el exponente más claro de esta redefinición del diálogo entre poder e historia venga constituido por la creación del oficio de cronista, que tiene lugar a comienzos del siglo Xv, y cuya importancia se consolida y amplía a lo largo de esa centuria. Aunque normalmente se tiende a contemplar los textos escritos por los cronistas oficiales como una simple muestra de propaganda, lo cierto es que una indagación sobre los oficiales y sobre sus historias pone de manifiesto una complejidad mucho mayor, que en realidad responde de forma más ajustada a la diversidad de los casos y a las tensiones que se suscitaron desde muy pronto en torno a este cargo $^{2}$. Si es cierto que la creación del oficio de cronista supone, entre otras cosas, un intento de control de la historia, no lo es menos que tal expediente estuvo lejos de asegurar automáticamente dicho control, al margen de que los conflictos en el interior de la corte tuvieron también su repercusión sobre el trabajo de los historiadores.

Los orígenes del cargo de cronista en Castilla son oscuros, pues carecemos de nombramientos y de detalles sobre sus funciones o su remuneración económica. El prólogo a la Primera Parte de la Crónica de Juan II asegura que a la muerte del anterior cronista, los tutores del rey, su tío Fernando de Antequera y su madre Catalina de Lancaster, "ordenaron estoriador que tomase las ystorias en el lugar e estado que fueron dexadas [...] e las feciese e ordenase según los fechos que adelante e después pasaron e pasasen ${ }^{3}$. Aunque no podemos tener total certeza de que este nombramiento correspondiera ya a un oficio burocrático, la explícita adjudicación a los tutores de la designación de un cronista invita a pensar que así sea. Un texto algo posterior, redactado por Álvar García de Santa María, arroja un poco más de luz a este respecto. Se trata de un prólogo en borrador, destinado seguramente a figurar al frente de la Segunda Parte de la Crónica de Juan II, cuya composición podría situarse tal vez en torno a $1433^{4}$. En él, Álvar García indica que el primer historiador de Juan II murió en 1420 y entonces el rey nombró a otro cronista, es decir, el propio Álvar García. Este texto ofrece algunas características similares a las del primer prólogo, entre las que destaca el anonimato que rodea a los historiadores, cuyos nombres no se desvelan en ningún momento. Ello hace que la autoría de la Primera Parte de la Crónica de Juan II sea, por ahora, desconocida, pero nos enfrenta a un primer

2 Véase la matizada posición de Kagan, Richard. Clio and the Crown: The Politics of History in Medieval and Early Modern Spain. Baltimore: Johns Hopkins University Press, 2009 (trad. Los cronistas y la Corona: la politica de la historia en España en las edades media y moderna. Madrid: Centro de Estudios Europa Hispánica, 2010, pp. 21-40). Kagan se centra sobre todo en los cronistas de los siglos XVI y XvII, mientras que mi propósito aquí es cubrir el siglo xv, en el que los problemas que rodean al cargo de cronista son tal vez mayores que en etapas posteriores.

3 Carriazo, Juan de Mata (ed.). Crónica de Juan II de Castilla. Madrid: Real Academia de la Historia, 1982, p. 4.

4 He editado y estudiado este texto en BautisTa, Francisco. «Álvar García de Santa María y la escritura de la historia». En Cátedra, Pedro M. (dir.). Modelos intelectuales, nuevos textos y nuevos lectores en el siglo XV: contextos literarios, cortesanos y administrativos: primera entrega. Salamanca: Seminario de Estudios Medievales y Renacentistas, 2012 [2014], pp. 27-59. 
momento en que este cargo parece haber sido más importante que los individuos que lo desempeńaban, e incluso en que la anonimia podría ser contemplada como una figura de la verdad.

Sea como fuere, el prólogo de Álvar García nos sitúa ya en un contexto institucional más seguro, al ofrecer algunos detalles sobre el nombramiento que aportan pistas además sobre los cometidos y responsabilidades de los cronistas. En primer lugar, se indica que el rey ordenó a los herederos del primer cronista que entregasen al nuevo historiador los papeles que tuvieran que ver con la historia:

Et enbio mandar et mando por su carta a los herederos del dicho estoriador primero que entregasen luego todo lo que el dicho estoriador finado tenia escripto e todas e qualesquier otras escripturas que del quedaran que a la dicha estoria pertenesçiese en qualquier manera ${ }^{5}$.

Se trata de una disposición que reaparece en situaciones análogas en el siglo XVI, y confirma que ya el predecesor de Álvar García ostentaba el oficio de cronista, de modo que la documentación que poseía podía considerarse no de su propiedad, sino de la corona $^{6}$. La segunda disposición tiene que ver con el envío al historiador de todas aquellas informaciones que pudieran serle útiles en su tarea:

Et mando otrosi por su carta a los infantes sus primos e a los perlados et duques e condes, ricos omnes e cavalleros et dotores e otrosi qualesquier personas del su consejo e de la su corte e de la su chançelleria e de las sus çiudades e villas e, a otros qualesquier personas de sus regnos, que dixesen e ynformasen al dicho segundo estoriador todas cosas que de los sus fechos suyos e de sus regnos ellos supiesen que el dicho estoriador entendiese que le cunplia ser ynformado, a fin que mejor et mas verdaderamente sin fallesçimiento alguno el pudiese fazer e ordenar la dicha coronica e estoria ${ }^{7}$.

Una petición similar figura en el primer nombramiento que se conserva, por el cual se hace cronista a Juan de Flores en 1474, y apunta a que ya en el caso de Álvar García hubo de existir un documento similar, que no se habría conservado ${ }^{8}$.

Justamente, el nombramiento de Juan de Flores alega como razones para su elección como cronista su "ydoneidad e sufiçiençia, fidelidad e abilidad, discreçion» y los servicios

5 Bautista, «Álvar García de Santa María», p. 32.

6 Véase, en el mismo sentido, la orden de Carlos V, dada el 7 de diciembre de 1526, a quienes pudieran tener papeles de Pedro Mártir: «El Rey - Qualquier persona o personas en cuyo poder quedaron y estan los libros y escripturas de Pedro Martir, nuestro coronista que fue, ya difunto, yo vos mando que, luego que con esta mi cedula fuerdes rrequeridos, deys y entregueys a fray Antonio de Guevara, mi coronista, la coronyca o historia que el dicho Pedro Martir dexó començada del descubrimiento [...] y otra qualquier coronyca que tenga fecha y encomençada de otra qualquier historia, para que el las prosiga y acave como por my le esta mandado" (en Morel-Fatio, Alfred. Historiographie de Charles-Quint: Première partie suivie des Mémoires de Charles-Quint. Paris: Honoré Champion, 1913, p. 27, n. 2).

7 Bautista, «Álvar García de Santa María», p. 32.

8 «E mandamos e rogamos a la prinçesa doña Ysabel [...] e a los ynfantes, perlados, duques, condes, marqueses [...] que vos ayan e tengan por nuestro coronista e usen con vos en el dicho ofiçio e comuniquen con vos las cosas a él tocantes»; documento editado por Bermejo Cabrero, José Luis. «Orígenes del oficio de cronista real». Hispania, 1980, vol. XL, pp. 395-409 (p. 408). 
FRANCISCO BAUTISTA PÉREZ

HISTORIOGRAFÍA Y PODER AL FINAL DE LA EDAD MEDIA: EN TORNO

AL OFICIO DE CRONISTA

anteriores prestados a la corona. Como ha señalado Elisa Ruiz García, «este cúmulo de cualidades aúna las relativas a la preparación técnica con las vinculadas a las necesidades políticas del momento»". En todo caso, lo esperable de alguna de ellas, como la lealtad, no debe ocultar el hecho de que desde sus comienzos, hasta donde podemos saber, el oficio recayó en individuos pertenecientes a la cancillería, generalmente escribanos o secretarios, cuyos servicios habían sido especialmente apreciados por el rey o por su entorno, y que poseían una plena familiaridad con este trabajo de tipo burocrático, como la expedición y el manejo de documentos. La pertenencia a la corte aseguraba su conocimiento directo de los hechos y de los individuos, y era por tanto un requisito indispensable para este oficio ${ }^{10}$. Así pues, las crónicas regias serán escritas a partir de ahora no por grandes señores, sino más bien por letrados, procedentes a veces de familias conversas, empleados previamente en puestos administrativos, y de los que paulatinamente se requerirá una formación más distinguida.

A pesar de sus aún inciertos orígenes y de su fragmentaria documentación, podemos entonces situar su creación en época de Juan II, con un primer nombramiento hacia 1407, tras la muerte de Pero López de Ayala, y un segundo en 1421, que tiene lugar tras el fallecimiento del anterior cronista. En la evolución del cargo se observa el paso de un único oficial, durante todo el reinado de Juan II, a un incremento de los titulares, ya que en la época de Enrique IV encontramos tres cronistas que desempeñan su labor de forma simultánea, y son varios también durante el reinado de los Reyes Católicos. Este aumento de los oficiales puede deberse a «la política de acrecentamiento de oficios» que caracterizó la segunda mitad del siglo Xv, aunque también es posible que se relacione con una consideración honorífica del cargo en algunos $\operatorname{casos}^{11}$. En efecto, de algunos de los cronistas, como Juan de Mena o Martín de Ávila, poseemos textos literarios o traducciones, pero ninguna obra histórica. Es posible que en casos como estos el nombramiento encubra una compensación por un tipo de labores intelectuales que no se corresponden exactamente con las cronísticas. A este respecto, se observa también una cierta variabilidad en el ejercicio del cargo, y esta es una característica que perdurará a lo largo del tiempo. Cabría pensar que justamente la existencia de varios oficiales simultáneos pretendiera sortear eventualidades de este tipo, aunque también es cierto que la pretensión de asegurar la existencia de al menos una crónica podía conllevar el riesgo de multiplicar los relatos ${ }^{12}$.

9 Ruiz García, Elisa. «El poder de la escritura y la escritura del poder». En Nieto Soria, José Manuel (dir.). Orígenes de la monarquía hispánica: propaganda y legitimación (ca. 1400-1520). Madrid: Dykinson, 1999, pp. 275-313 (cita en p. 284).

${ }_{10}$ Así lo muestra Álvar García, quien destaca justamente su larga pertenencia a la corte y sus servicios al rey: «el dicho estoriador era asaz ynformado dello como aquel que avia veynte e çinco años que continuava la corte, e non se partia della si pudiese salvo quando yva por mandado del rey o de los del su consejo a algunas partes que cunplia a su serviçio» (Bautista, «Álvar García de Santa María», p. 32).

11 Bermejo Cabrero, «Orígenes del oficio de cronista real», p. 399.

12 Con ello se podría relacionar tal vez un comentario de Fernando del Pulgar dirigido a Isabel I: «Todo esto [todo lo que debe escribirse en una crónica] muy esçelente rreyna e senora no es rrazon dexarlo a esamen de un çelebro solo, aunque fuese bueno, pues ha de quedar por perpetua memoria» (Pulgar, Fernando del. Letras, ed. de Paola Elia. Pisa: Giardini, 1982, p. 62). Es cierto que Pulgar se refiere a su voluntad de mostrar su crónica a la reina para que ella la revise, pero una consideración similar podría estar en la base de la concesión del cargo a varios cronistas. Más adelante tendrá lugar una cierta especialización del trabajo de estos, pero aun así siguieron existiendo varios oficiales para tareas similares. 
FRANCISCO BAUTISTA PÉREZ

HISTORIOGRAFÍA Y PODER AL FINAL DE LA EDAD
AL OFICIO DE CRONISTA

El citado texto de Álvar García abre algunas perspectivas sobre el tipo de trabajo del cronista. Así, este parece situado en el centro de las informaciones en el reino, pues se solicita de los naturales que le envíen todo aquello que pueda serle de interés para la historia. Como he señalado, el nombramiento de Juan de Flores en 1474 insiste en esta misma idea, y tenemos pruebas de que en efecto el cronista había de recibir noticias diversas, en particular sobre aquellas situaciones en las que no se encontraba presente ${ }^{13}$. Al mismo tiempo, dada la proximidad de los oficiales con la cancillería, de la que a menudo forman parte como escribanos o secretarios, será común a partir de ahora el uso o la inclusión de documentos en las historias, que constituyen una suerte de prueba o de evidencia que tiene valor en sí misma. Por otro lado, es probable que uno de los nuevos géneros historiográficos del siglo Xv, la «epístola de relación», se desarrollase justamente al calor de estas nuevas necesidades, no solo en virtud de su capacidad propagandística, sino también en función de su eventual aprovechamiento en las crónicas regias ${ }^{14}$.

Ya a comienzos del siglo XvI, un pasaje de la obra de Andrés Bernáldez proporciona indicios suplementarios sobre la íntima conexión entre las tareas cancillerescas y las labores de los cronistas:

Como sea parte del oficio de los coronistas, en servicio de los reyes sus señores, de expedir epístolas en su servicio, en los tiempos que conviene, para saber lo que se haze en otros reinos, e acoger las respuestas e tomar de ellas aquello que a su oficio conviene de algunas cosas hazañosas, e aver conocimiento de los reyes comarcanos e de sus coronistas, por intercesión de letras, para ingerir en las corónicas algunas cosas de las que acaecen en sus tiempos, las de acullá e las de acá, que convienen por la verificación ser assí escritas [... ${ }^{15}$.

Este fragmento, que antecede a la inclusión de una epístola de Fernando del Pulgar a Alfonso V de Portugal cuando este pretendía entrar en Castilla defendiendo sus derechos al trono, habla también de la participación activa de los cronistas en las negociaciones. En este sentido, el texto de Bernáldez no solo ratifica la posición del historiador en el centro de una red de comunicaciones, sino además su implicación misma en los hechos a través de gestiones diplomáticas o embajadas, y de su intercambio con los cronistas de otros reinos.

Esta idea del cronista como actor está estrechamente ligada a la construcción de un relato que versa sobre la historia contemporánea. Al calificar su trabajo, Álvar García de Santa María habla de su posición como "estoriador destos presentes tienpos»" ${ }^{16}$ y una de las categorías que emerge frecuentemente es la del testimonio, la de que el cronista habla de aquellos hechos en los que estuvo presente o de los que obtuvo testimonio de personas fiables, como había señalado ya Pero López de Ayala. Ahora, sin embargo, el testimonio queda acotado o pautado por una red de documentos que complementan

13 Véase Bautista, «Álvar García de Santa María».

14 Cátedra, Pedro M. "En los orígenes de las epistolas de relación». En Las «relaciones de sucesos» en España (1500-1750): Actas del Primer Coloquio Internacional (Alcalá de Henares, 8, 9 y 10 de junio de 1995). Paris: Publications de la Sorbonne; Alcalá de Henares: Servicio de Publicaciones de la Universidad de Alcalá, 1996, pp. 33-64.

15 Bernáldez, Andrés. Memorias del reinado de los Reyes Católicos, ed. de Manuel Gómez-Moreno y Juan de M. Carriazo. Madrid: Real Academia de la Historia, 1962, pp. 38-39.

16 Bautista, «Álvar García de Santa María», p. 31. 
FRANCISCO BAUTISTA PÉREZ

HISTORIOGRAFÍA Y PODER AL FINAL DE LA EDAD MEDIA: EN TORNO

AL OFICIO DE CRONISTA

el punto de vista personal, y lo transfieren a una escritura que se confunde con los hechos. Pero aunque el peso testimonial queda amortiguado por ese deseo de construir una historia autorizada, sí perdura la idea de que el cronista debe contar, y no tanto juzgar, como seńala Lorenzo Galíndez de Carvajal:

Es verdad quel oficio de cronista como el del testigo e escribano no es de juzgar y glosar los hechos, mas solamente recontarlos como pasaron ${ }^{17}$.

En el ámbito del testimonio veraz, el cronista queda emparentado en varios textos con los evangelistas. Así, Juan de Flores afirma que los cronistas son «evangelistas temporales», y más adelante Gonzalo Fernández de Oviedo escribe que el de historiador "officio es de evangelista» ${ }^{18}$. Esta sacralización de la tarea del cronista no solo implica una mistificación del poder sobre el que trata, sino que además parece llamada a conjurar los problemas que podrían surgir en todo testimonio, en tanto que parcial, apasionado o indemostrable, y de este modo constituiría un síntoma de esa ansiedad sobre la verdad histórica que recorre todo el siglo Xv.

No disponemos de informaciones explícitas sobre las causas de la creación de este oficio. Si bien es cierto que en otros ámbitos políticos se dará el mismo paso, no lo es menos que la iniciativa castellana se cuenta entre las primeras, al menos por cuanto sabemos hasta ahora ${ }^{19}$. José Luis Bermejo Cabrero señaló que se debería fundamentalmente a dos razones: en primer lugar, un aumento de la importancia de la historia como instrumento de reflexión y formación política; y, en segundo lugar, el desarrollo del aparato administrativo de la monarquía, que no hace sino crecer desde la época de Juan $\mathrm{II}^{20}$. En el mismo sentido, Bernard Guenée propuso como causas la progresiva autonomía de la historia frente al derecho o la teología y el desarrollo de la burocracia. De igual modo, indicaba que el deseo de construir historias autorizadas y fiables hubo de conducir a vincular estrechamente la escritura de la historia a la administración, pues la crítica histórica de la época entendía que los textos aprobados y auténticos, como la documentación, eran más fiables ${ }^{21}$. Junto a estas motivaciones, puede verse también en la creación del oficio de cronista una voluntad de controlar la representación del presente y del pasado, voluntad que cabe poner en relación con el creciente poder del escrito y de la opinión en la sociedad bajomedieval.

17 Galíndez de Carvajal, Lorenzo. Prólogo a la Crónica de don Juan II. En Rosell, Cayetano (ed.). Crónicas de los reyes de Castilla. Madrid: Rivadeneyra, 1878, vol. II, p. 274a. Galíndez parece inspirarse aquí en un conocido pasaje de Quintiliano: «scribitur ad narrandum, non ad probandum» $(10,1,31)$.

18 TATE, Robert B. «La historiografía del reinado de los Reyes Católicos». En Codoñer, Carmen y González Iglesias, Juan Antonio (eds.). Antonio de Nebrija: Edad Media y Renacimiento. Salamanca: Ediciones Universidad de Salamanca, 1994, pp. 17-28 (en p. 19); y AGnew, Michael. "Evangelista temporal: The Limits of Historiographical Discourse in Juan de Flores's Royal Chronicle». En Gwara, Joseph J. (ed.). Juan de Flores: Four Studies. Londres: Department of Hispanic Studies, Queen Mary, University of London, 2005 , pp. 11-47.

19 Tate, Robert B. "The Official Chronicler in the Fifteenth Century: A Brief Survey of Western Europe». Nottingham Medieval Studies, 1997, vol. XLI, pp. 157-185.

20 Bermejo Cabrero, "Orígenes del oficio de cronista real», p. 396.

21 Guenée, Bernard. Histoire et culture historique dans l'Occident médiéval. Paris: Aubier, 1980, p. 345. 


\section{FRANCISCO BAUTISTA PÉREZ

De la fuerza política de los textos escritos da cuenta el número y la importancia de los manifiestos que circularon en esta época, fundamentales en los enfrentamientos entre bandos y facciones dentro de la corte, o en los conflictos fronterizos que tuvieron lugar en la península Ibérica. Tales manifiestos testimonian la relevancia de la opinión como instrumento de legitimación de una causa. Abundan las referencias al peso efectivo de tal opinión en el desarrollo de ciertos hechos, o en el éxito o fracaso de algunas empresas. A veces se trata de un mero rumor, que se va extendiendo hasta dar lugar a reacciones diversas. Es lo que sucede con los problemas en la corte durante la minoría de Enrique III, según cuenta la Crónica anónima de este rey, redactada probablemente a comienzos del siglo Xv:

E como por todas partes discurriesen e fuesen preguntados lo que se rresumia, cada vno ynventava y deçia lo que le pareçia, de do se publico y estendio nuevas por todo el rreyno del levantamiento entre los grandes por las opiniones de cada vno. Y las gentes nezesitadas y mal asentadas lo publicavan mas, de do se enpeço a tomar desasosiego y escandalos en muchas çibdades e villas prençipales del rreyno, e zesando los tratos, aperçeviendose de armas y de parçialidades, que no poco dańo cavso en el rreyno 22 .

Esta publicación de noticias, ya sea a través de la oralidad o de la escritura, se convierte entonces en una de las preocupaciones políticas en el siglo XV, y entre las tentativas de control ha de contarse seguramente la creación del cargo de cronista.

Años más tarde, en 1446, una carta de Alfonso V de Aragón a su hermano Juan II de Navarra da cuenta de esa conciencia de la importancia de la opinión para el gobierno. Ante el proyecto del segundo de tratar de recuperar la influencia en Castilla, Alfonso V le aconseja cautela y le dice:

Piensa que oy el mundo se rije en la maior parte por opinion e son mas aquellas cosas que se dudan que equellas (sic) que nuecen ${ }^{23}$.

En el manejo de la opinión jugarán un papel central los textos escritos, muchos de ellos efímeros, pero también en ese marco debe entenderse la redefinición del papel de la historiografía, a la que se trata de dotar de mayor autoridad, utilidad y dirección al integrarla dentro de los oficios ligados al gobierno.

Ahora bien, como he adelantado, no puede decirse que ello eliminase las tensiones entre el poder regio y la escritura de la historia. Tanto por lo que hace a los cronistas como a los textos o a los debates que se produjeron, este nuevo oficio se convirtió en uno de los puntos neurálgicos en las discusiones historiográficas del siglo xv. Por un lado, la autenticidad que se suponía al relato salido de la pluma de los cronistas oficiales convirtió a estos en personajes situados en el ojo del huracán, expuestos a la destitución, el pillaje o el ostracismo. Por otro, los textos mismos escritos por estos oficiales fueron en ocasiones objeto de reescrituras, con el fin de acomodarlos a distintas

22 García, Michel (ed.). Crónica anónima de Enrique III de Castilla (1390-1391). Madrid: Marcial Pons, 2013, p. 55.

23 Giménez Soler, Andrés. Itinerario del rey Alfonso V de Aragón y I de Nápoles. Zaragoza: Mariano Escar, 1909, p. 230. 
FRANCISCO BAUTISTA PÉREZ

HISTORIOGRAFÍA Y PODER AL FINAL DE LA EDAD MEDIA: EN TORNO

AL OFICIO DE CRONISTA

perspectivas o intereses. Por último, si uno de los objetivos del cargo de cronista había sido la construcción de una historia auténtica y aprobada, muy pronto se levantaron voces que ponían de manifiesto los grandes problemas que presentaba ese nuevo modelo, y que hacían sospechosos o poco fiables los textos de los cronistas oficiales. Es más, puede decirse que al hilo de la creación y consolidación de este cargo se desarrollaron otras formas historiográficas, en ocasiones como una suerte de alternativa o de contestación a las crónicas regias.

Es obvio que la elección de los cronistas recaería sobre individuos estrechamente vinculados a la corona, sobre cuya lealtad no habría en principio dudas. Ahora bien, las circunstancias en las que se había producido un nombramiento y el desarrollo posterior de los hechos podían dar lugar a tensiones e incluso a enfrentamientos. Álvar García fue designado cronista en 1421, y es muy probable que su candidatura fuera propuesta por el infante don Juan, para quien aquel venía actuando como contador mayor al menos desde 1417. Es cierto que se trataba de un individuo apto para el cargo, integrado desde hacía tiempo en la cancillería castellana, primero como escribano, en 1408, y luego como encargado del registro, desde 1412. Ahora bien, Álvar García, cuya minuciosa y equilibrada crónica se extiende de 1420 a 1434, debió quedar desde 1429 en una posición delicada, dado el enfrentamiento de su antiguo valedor, ahora rey de Navarra, con Álvaro de Luna, quien se convirtió a partir de ese año en el agente político más importante en Castilla. Aunque Álvar García figura como cronista todavía en 1440, su toma de partido en el conflicto que se cerrará con la batalla de Olmedo cinco ańos después lo dejará en el bando derrotado ${ }^{24}$. No tenemos ninguna documentación sobre su destitución, pero es seguro que dejó de trabajar en la crónica poco después de 1437 y ya no retomó esa labor, de la que hubo de ser relegado precisamente por su alineamiento con el bando contrario a Álvaro de Luna. Poco después de 1445 ya había otro cronista, Juan de Mena, de quien en todo caso no conocemos ninguna historia sobre Juan II. Así pues, el nombramiento de Álvar García no implicó su adhesión sin fisuras a la política del rey, y en particular a la figura de Álvaro de Luna, lo que en última instancia acabó apartándolo del cargo.

Durante la época de Enrique IV, el incremento de oficiales y el aumento de la conflictividad en la corte dieron lugar a alguna situación en la que los enfrentamientos afectan directamente a la crónica regia. Es el caso bien conocido del robo de los papeles del cronista Diego Enríquez del Castillo y la detención de este cuando el partido del príncipe Alfonso toma la ciudad de Segovia en 1467. El propio Enríquez del Castillo se refiere a ello en el prólogo a su crónica, para justificar la brevedad o las lagunas en la parte anterior a ese año. Allí escribe: «me rrovaron, no solamente lo mío, mas los rregistros con lo proçesado que tenía escripto de ella $»^{25}$. Alfonso de Palencia, situado en el bando alfonsista, alude a estos hechos con un poco más de detalle, señalando que leyó el relato de la batalla de Olmedo que había tenido lugar cuarenta días atrás y que se encontró que

24 Cantera Burgos, Francisco. Álvar García de Santa María y su familia de conversos: historia de la Judería de Burgos y de sus conversos más egregios. Madrid: Instituto Arias Montano, CSIC, 1952, pp. 159-162.

25 Enríquez del Castillo, Diego. Crónica de Enrique IV, ed. de Aureliano Sánchez Martín. Valladolid: Universidad, 1994, p. 132. 
FRANCISCO BAUTISTA PÉREZ

todo lo escrito era mentira ${ }^{26}$. Los papeles quedaron en manos de Alfonso Carrillo, arzobispo de Toledo, y el príncipe Alfonso llegó a decretar la muerte de Enríquez del Castillo, aunque lo salvó su pertenencia a la iglesia ${ }^{27}$. Más tarde, Palencia alega que la falsedad de esos borradores fue uno de los impulsos que están en su obra, que adquiere así, para esos años, una dimensión de contestación o de contra-historia ${ }^{28}$.

No siempre el oficio de cronista conllevaba tan altos riesgos, pero hay que reconocer que Enríquez del Castillo no fue el más afortunado. Al cabo de cuatro meses de la llegada de Isabel al poder, hacia marzo de 1474, esta comunicó al antiguo historiador de su hermano, por medio de su secretario Alonso de Ávila, que dejaría de recibir la remuneración de cronista. Enríquez del Castillo escribió entonces una extensa carta en la que declara su lealtad a la corona y le ruega que le readmita en el cargo, prometiéndole la misma fidelidad que tuvo con Enrique IV:

Sy algo yo predique en ayuda y fauor de vuestros aduerssarios, no fue ni pudo ser cosa que a vuestro seruiçio cumpliese, pero ni por eso se sigue que vuestra çelsitud deua estar indynada ni enojada contra mi. Antes con magnanimidat loar y agradeçer, tener por bien lo que hize, no menos ni mas que a los muy affecçionados, a los muy parçiales de vuestra opinion y parte, porque sy con el vando contrario, quando suyo me halle, hize lo que deuia, tanto bien y mejor lo hiziera en seruiçio de vuestra altesa, sy con tantos vituperios, con tantas portadas no me echara de su casa ${ }^{29}$.

De poco le sirvieron sus quejas y protestas, ya que Enríquez del Castillo quedó definitivamente relegado de su oficio de cronista. Su declarado propósito de enmienda no tuvo efecto sobre la reina, que prefería oficiales con una lealtad probada en los tiempos difíciles. Del mismo modo que cada nuevo rey traía consigo su Merlín, como había criticado años atrás Gutierre Díaz de Games, no había duda de que la reina traía consigo sus propios cronistas ${ }^{30}$.

No todos ellos, sin embargo, navegaron sin dificultad el oficio. El díscolo Alfonso de Palencia, que se definía a sí mismo como "cultor ueritatis»" ${ }^{31}$, fue separado, si no de su cargo, sí de la corte y del acceso a la documentación cancilleresca en las Cortes de Toledo de 1480. De acuerdo con su propio relato, en aquella ocasión la reina observó que era conveniente y justo que cuanto él escribiera fuera sometido a la censura; Palencia trató de defender su independencia con diversos argumentos, y en un primer momento pareció que estos habían satisfecho a Isabel. Sin embargo, continúa el autor, fue evidente después que todos

26 Nótese que poco más de un mes después de los hechos Enríquez del Castillo ya había preparado una narración sobre esos hechos: la historia es así casi un registro del presente.

27 Palencia, Alfonso de. Gesta Hispaniensia ex annalibus suorum dierum collecta, ed. de Brian Tate y Jeremy Lawrance. Madrid: Real Academia de la Historia, 1998-1999, vol. II, pp. 454 y 483.

28 Palencia, Gesta Hispaniensia, vol. I, p. 2 y notas (pp. 32-33).

29 Paz y Melia, Antonio. El cronista Alonso de Palencia. Madrid: The Hispanic Society of America, 1914, p. lxxxvii.

30 «E si bien paras mientes, como viene rey nuevo, luego fazen Merlín nuevo» (DíAz DE GAMES, Gutierre. El Victorial, ed. de Rafael Beltrán. Salamanca: Ediciones Universidad de Salamanca, 1997, p. 325).

31 Palencia, Gesta Hispaniensia, vol. I, p. 2. 
FRANCISCO BAUTISTA PÉREZ

HISTORIOGRAFÍA Y PODER AL FINAL DE LA EDAD MEDIA: EN TORNO

AL OFICIO DE CRONISTA

los servicios del cronista «se desvanecieron en el aire» ${ }^{32}$. Retirado en Sevilla, Palencia siguió trabajando en su proyecto historiográfico y mantuvo su puesto de cronista, pero perdió su influencia y su acceso privilegiado a las decisiones e informaciones de la corte. En este caso, su predilección por Fernando y sus críticas a la reina, que no tuvo cuidado en ocultar, habían acabado por aislarlo. En último término, la independencia de la que hace gala en las Cortes de Toledo y a lo largo de toda su obra lo convertía en un historiador incómodo, a quien la reina Isabel consideró más útil apartado de la corte.

El deseo de supervisar el texto de la crónica, al que Palencia se resistía, se pone de manifiesto en una de las cartas de Fernando del Pulgar a la reina (Letra XI), en la que, además de elogiar a Isabel por su atención hacia estos menesteres, le manifiesta la conveniencia de que el relato que él escribe sea examinado por ella misma o por individuos de su confianza:

Yo yré a vuestra alteza segund me lo enbía a mandar e llevaré lo escrito fasta aquí para que lo mande examinar [...] y es cosa muy rrazonable que vuestra persona rreal se glorifique en leer vuestras cosas, pues son dygnas de exemplo e doctrina para vuestros descendientes en especial e para todos los otros en general ${ }^{33}$.

Aquí Pulgar se nos presenta como un oficial abnegado y dócil, que somete su crónica al juicio de la reina o de otros letrados designados por ella a tal efecto. Esta carta muestra, además, como en el caso de Enríquez del Castillo, que la redacción del texto se iba llevando a cabo al hilo de los hechos, sin esperar a tener una perspectiva distanciada sobre los mismos. Práctica que se documenta ya en los cronistas de Juan II y que constituye una de las novedades más sobresalientes, frente a las historias medievales anteriores, al establecer una estricta contemporaneidad entre la escritura y los hechos.

Justamente, no mucho después de la citada carta de Pulgar se crearía un nuevo cargo relacionado con la historia, en este caso dedicado a la censura y revisión de los textos, en la persona de Lorenzo Galíndez de Carvajal. Con ese título se refiere a él Juan de Rihuerga ("censor de las coronicas que en los tienpos presentes se escriven del rey nuestro señor y sus reinos»), cuando en 1525 le envía su Crónica de las antigüedades de España, para que la lea y ordene su impresión si la juzga útil para el reino ${ }^{34}$. No sabemos exactamente el papel que desempeñó Galíndez de Carvajal en tanto que censor de las crónicas de Carlos $\mathrm{V}$, pero sí conocemos un amplio programa suyo para la impresión de textos historiográficos previos, del que solo llegó a publicarse el volumen correspondiente a la Crónica de Juan II en 1517. Al frente de tal crónica, y en otro prólogo a su sumario de la historia de los Reyes Católicos, este autor proporcionó una valoración de la cronística sobre ambos periodos que constituye tal vez el primer

32 López de Toro, José (ed. y trad.). Cuarta década de Alonso de Palencia. Madrid: Real Academia de la Historia, 1970-1974, vol. I, p. 167; vol. II, p 196. Sobre el pasaje en cuestión, debe verse TATE, Robert B. «Alfonso de Palencia y los preceptos de la historiografía». En García de la Concha, Víctor (ed.). Nebrija y la introducción del Renacimiento en España. Salamanca: Ediciones Universidad de Salamanca, 1983, pp. 37-51 (p. 42).

33 Pulgar, Letras, pp. 62-63.

34 Biblioteca Nacional de España, ms. 1496, fol. 81v. 
FRANCISCO BAUTISTA PÉREZ

HISTORIOGRAFÍA Y PODER AL FINAL DE LA EDAD MEDIA: EN TORNO

intento de llevar a cabo una historia de la historiografía castellana. Aunque el cargo de «censor» no parece haber tenido la misma continuidad que el de cronista, responde a ese mismo deseo de controlar y autorizar los textos que se pone de manifiesto en las intervenciones de la reina Isabel en relación con Palencia y Pulgar. Indica, en fin, que la creación del oficio de cronista no parecía suficiente desde la perspectiva del poder regio, y muestra un aumento de los instrumentos de supervisión de la escritura histórica, donde se mezcla el objetivo de rastrear y divulgar los mejores textos con el de lograr una mayor eficacia en la consecución de una auténtica historia oficial.

En verdad, la revisión o la reescritura de los textos fue una tentación constante a lo largo del siglo xv, y quizá contra ella se crease también este oficio de censor, con el fin de separar lo auténtico de lo falso, lo original de las copias deturpadas o interpoladas. Ya en época de Juan II tenemos un caso de este tipo de reescritura, efectuada en el ámbito de la corte. Poco tiempo después de que Álvar García entregase al rey el relato que cubre los ańos 1420 a 1434, otro individuo, cuya identidad desconocemos, intervino en el texto, añadiendo detalles elogiosos sobre Álvaro de Luna, que por momentos convertían la historia en un panegírico del privado del rey ${ }^{35}$. Esta intervención es a veces difícil de precisar y aislar, ya que para una buena parte del texto carecemos del original del cronista, pero la información sobre tal intervención hubo de difundirse desde la corte y de ella se hace eco Fernán Pérez de Guzmán en el prólogo a sus Generaciones y semblanzas, obra escrita entre 1455 y 1460 :

La estoria le fue tomada [a Álvar García] e pasada a otras manos e segund las ambiçiones desordenadas que en este tienpo ay, razonablemente se deve temer que la corónica non esté en aquella pureza e sinpliçidad que la él ordenó ${ }^{36}$.

En este sentido, los textos tampoco estaban a salvo de las banderías que recorren el siglo $\mathrm{Xv}$, de modo que el intento de construir una historia autorizada se vio a veces puesto en entredicho por estas actuaciones que convertían en sospechosas esas mismas crónicas regias.

Galíndez de Carvajal proporciona otros dos ejemplos del peligro que amenazaba a los textos, vinculados en este caso al tiempo de los Reyes Católicos. Tratando de la crónica de Fernando de Pulgar, que juzga con dureza, señala que al margen de sus propios defectos algunos ejemplares de esta obra llevaban interpolaciones de otro individuo:

Ovo otra desdicha esta corónica de Pulgar, que cayó originalmente en manos de otra persona principal, el cual hizo en su cosa propia algunas adiciones, como le plugo, las cuales, puesto que fuera verdad, como es de creer, era especie de falsedad e grande ambición ponerlas por su autoridad en corónica de tan altos Príncipes, aunque algo le excusa la escaseza y brevedad del coronista ${ }^{37}$.

35 Bautista, Francisco. "La segunda parte de la Crónica de Juan II: borradores y texto definitivo». Cahiers d'Études Hispaniques Médiévales, 2014, vol. XXXVII, pp. 105-138.

36 Pérez de Guzmán, Fernán. Generaciones y semblanzas, ed. de Robert B. Tate. London: Tamesis, 1965, pp. 3-4.

37 Rosell (ed.), Crónicas de los reyes de Castilla, vol. III, pp. 536-537. 
No sabemos muy bien cuáles fueron las adiciones de las que habla Galíndez de Carvajal, ya que aún carecemos de un estudio sistemático de la tradición manuscrita de la crónica de Pulgar, y desconocemos igualmente la identidad del interpolador, pero este caso ejemplifica la fragilidad de los textos, que, a pesar de su oficialidad, no estaban libres de correcciones o intervenciones ajenas ${ }^{38}$.

A veces, los efectos sufridos por obras que no satisfacían las expectativas, ya no de los reyes, sino de algunos nobles, podían ser mucho más graves. Es lo que, de acuerdo con el testimonio de Galíndez de Carvajal, sucedió con la historia en verso sobre la guerra de Granada de Hernando de Ribera, de la que no se conoce en la actualidad ningún testimonio. Era, a juicio del rey Fernando, la mejor historia sobre esos hechos, según cuenta el propio Galíndez de Carvajal, «porque en pasando algun hecho o acto digno de escribir lo ponia en coplas y se leia a la mesa de su Alteza, donde estaban los que en lo hacer se habian hallado, e lo aprobaban o corregian, segun en la verdad se habia pasado». Aquí emerge una visión de la autoridad del relato en función de su aprobación colectiva. Sin embargo, el que esa verdad no dejase satisfecho a alguno de los cortesanos podía ser suficiente para poner en peligro la obra. Así, Enrique Enríquez, no contento con la omisión de un suceso secundario y azaroso que le afectaba, se hizo con el texto y lo modificó a su antojo:

Dende algunos días imbió por la corónica que estaba en un monasterio, y casi que por fuerza la sacó y quitó lo que quiso, y lo que dejó no se puso arriba, porque la corónica no quedó tan cumplida, ni en la sinceridad que Ribera lo escribió ${ }^{39}$.

De este modo, los mismos textos cronísticos se convirtieron en ocasiones en un auténtico campo de batalla, donde se decidían los conflictos políticos en el seno de la corte o la desmedida y violenta codicia de fama de algunos nobles. Pero debe notarse también que ese interés por la crónica regia reside seguramente en su condición de relato autorizado y aprobado, cuyo poder legitimador era visto como superior al resto de discursos históricos, lo que la hacía objeto de los deseos de reyes, privados y nobles.

Como señalaba antes, es muy posible que una de las razones de la creación del cargo de cronista fuera en efecto la de lograr una mayor autoridad para los textos históricos. Así lo indica Bernard Guenée:

Les principes mêmes de la critique historique médiévale encouragèrent certains de ces pouvoirs à concevoir les avantages d'une histoire authentique, à explicitement couvrir de leur autorité des récits qui leur étaient favorables, à patroner, sans complexes, des histoires officielles ${ }^{40}$.

38 Véase lo señalado por Pontón, Gonzalo. «Fernando de Pulgar y la Crónica de los Reyes Católicos». En Pulgar, Fernando del. Crónica de los Reyes Católicos, ed. de Juan de Mata Carriazo. Granada: Universidad, 2008, vol. I, pp. lxxxv-lxxxvi.

39 Rosell (ed.), Crónicas de los reyes de Castilla. vol. III, p. 537. Nótese que Galíndez se hace eco de la expresión de Pérez de Guzmán al hablar sobre la intervención en la Crónica de Juan II.

40 Guenée, Histoire et culture historique, p. 339. 
FRANCISCO BAUTISTA PÉREZ

HISTORIOGRAFÍA Y PODER AL FINAL DE LA EDAD MEDIA: EN TORNO

Obviamente, esta autenticidad estaba destinada a una mayor eficacia de los relatos, que en principio habían de sustentar las causas de quienes los patrocinaban, aunque en la realidad, como hemos visto, las cosas no fueran tan sencillas. Pero todo indica que el expediente consiguió dotar efectivamente de una mayor autoridad a estas nuevas crónicas, lo que tal vez esté detrás de los intentos de modificar o alterar esos textos. Es sabido que la historiografía se caracteriza por su apertura y su fluidez, y que muchas de las obras se nos han conservado en varias redacciones, pero la creación del oficio de cronista suponía en cierta medida una concepción distinta de la tradición, por la cual los textos quedaban ceñidos al cronista y circunscritos a su intervención, y ello está detrás probablemente de la puntualidad con la que Pérez de Guzmán y Galíndez de Carvajal levantan acta de esos cambios o intervenciones.

Ahora bien, si se trataba de un expediente de autorización de la historiografía ligada a la corona, muy pronto surgieron voces que denunciaban la nueva situación justamente como una amenaza para la credibilidad de los textos. La pieza más conocida en este sentido es el prólogo de Pérez de Guzmán a sus Generaciones y semblanzas, donde señala:

Muchas vezes acaesçe que las corónicas e estorias que fablan de los poderosos reyes e notables prínçipes e grandes çibdades son avidas por sospechosas e inçiertas e les es dada poca fe e abtoridat ${ }^{41}$.

Tras precisar que en algunos casos ello se debe a la fabulación deliberada de algunos autores, agrega otra causa, vinculada directamente a las crónicas que tratan sobre el tiempo presente:

El segundo defeto de las estorias es porque los que las corónicas escriven es por mandado de los reyes e prínçipes. Por los conplazer e lisonjar o por temor de los enojar, escriven más lo que les mandan o lo que creen que les agradará, que la verdat del fecho como pasót ${ }^{4}$.

En este prólogo, Pérez de Guzmán arremete directamente contra la creación del oficio de cronista y denuncia una situación que será una constante fuente de dudas y suspicacias a lo largo del siglo Xv. Los cronistas oficiales estaban en una posición privilegiada para conocer los hechos, por su acceso a la documentación y a los protagonistas, pero al mismo tiempo podían ver limitada su libertad de juicio por las presiones del entorno que les había encomendado esa tarea. Ya hemos visto que, si bien esto no sucedió así en todos los casos, es común que los oficiales pagasen la defensa de su independencia con su destitución o su alejamiento del poder. Y más adelante se llegará a plantear una supervisión directa sobre los textos, como muestra el testimonio de Pulgar y la creación del oficio de censor en la persona de Galíndez de Carvajal.

No hay que perder de vista que el prólogo de Pérez de Guzmán abre un conjunto de retratos que se proponen en realidad como una historia alternativa sobre el reinado de Juan II, de modo que la crítica de la cronística regia es fundamental para justificar su propia tarea. Pero algunas de sus observaciones tuvieron una indudable influencia. Este

41 Pérez de GuZmán, Generaciones y semblanzas, p. 1.

42 Pérez de GuzMán, Generaciones y semblanzas, p. 2. 
autor establece tres criterios para garantizar una mayor autoridad a las obras históricas. Dos de ellos tienen que ver con el cronista, y en cierta medida enlazan con ideas ya expuestas con anterioridad. Así, Pérez de Guzmán apunta que ha de ser un individuo instruido y que debe estar en contacto directo con los hechos que narra. En cierta forma, estas ideas están ya en el prólogo de Álvar García de Santa María, quien indica que el cronista debe guardar dos reglas:

La primera es que la obra que sea buena e que razonablemente se pueda esperar della buen fruto. La segunda es que aquel que la ordena sea tal persona por sus meresçimientos que con verdat la pueda fazer ${ }^{43}$.

A pesar de que se enuncian aquí con poca precisión, subyace ya en estos dos preceptos, centrados en la utilidad y verdad de la historia, un intento de acotar un espacio propio para el cronista, que le permita escribir su obra con una cierta autonomía.

Álvar García se refiere también al cuidado en la elección del cronista, que ha de atender a sus merecimientos, pero también a su capacidad para escribir con verdad. Se trata de un asunto evocado igualmente por Galíndez de Carvajal, quien parece preferir que el oficio recaiga sobre grandes seńores, y no sobre letrados, quienes carecen de poder para imponer su criterio:

Mucho se habia de mirar en la elección de la persona que ha de escribir la corónica, que fuese nombrada por el Príncipe con aprobación de muchos, pues se hace de perjuicio de tantos, y no dar lugar que cada uno fácilmente se ingiriese a escribir lo que le place en loor de pocos, y en perjuicio de todos; y en tal elección se habia también de mirar el bien de la legalidad de la persona, que el elegido fuese de buena parte; porque ni temor de los poderosos, ni afición de su gente le hiciesen apartar de la verdad. E ansí vemos que se hizo en los tiempos pasados en la ley divina y humana, y en nuestros tiempos, que fueron coronista Pero López de Ayala y Hernán Pérez de Guzman ${ }^{44}$.

Esta postura un tanto nostálgica de Galíndez de Carvajal trataba así de asegurar el equilibro en la escritura de la historia, que vendría dada por la independencia política que otorgaría al cronista su pertenencia a una gran familia. En todo caso, no fue una sugerencia que tuviese gran eco, ya que el nombramiento de los cronistas siguió recayendo predominantemente sobre letrados y humanistas.

Como tercer antídoto contra el descrédito de la historia, Pérez de Guzmán señala que no ha de publicarse en vida del príncipe, para que el cronista pueda escribir con libertad sobre sus hechos:

La terçera es que la estoria que non sea publicada biviendo el rey o prínçipe en cuyo tienpo e señorío se hordena, por quel estoriador sea libre para escrivir la verdad sin temor ${ }^{45}$.

43 Bautista, «Álvar García de Santa María», p. 30.

44 Rosell (ed.), Crónicas de los reyes de Castilla, vol. III, p. 536.

45 Pérez de GuzMán, Generaciones y semblanzas, p. 2. 
FRANCISCO BAUTISTA PÉREZ

Esta sugerencia toca directamente el problema de la supervisión de los textos, pero la evolución del oficio de cronista muestra en realidad un itinerario que va en la dirección contraria, como hemos visto en el caso de Isabel I y Pulgar. Ya no solo es que la historia se publique en vida del rey, como sucedió probablemente con la Segunda Parte de la Crónica de Juan II, sino que los textos van siendo sometidos a revisión y censura a medida que el cronista los redacta.

La recomendación de Pérez de Guzmán obviamente no garantizaba la independencia del cronista frente al poder regio, aunque sí podía favorecerla. Quizá este carácter secreto de la historia explique la originalidad de la obra de Alfonso de Palencia en su contexto. En ella abundan las descripciones de intrigas, la crítica de los diferentes estados, desde los reyes hasta el pueblo, y en general una visión bastante negativa de su época, de la que muy pocos escapan. Es quizá todo ello lo que llevó a Jerónimo Zurita a juzgar duramente a Palencia, a quien acusó de escribir «no solo muy atrevidamente, sino con mucha deshonestidad»" El propio Zurita señaló con perspicacia que una de las razones de la singularidad de la obra de Palencia habría residido en redactar su obra en latín, lo que le permitió escribir con mayor libertad que a otros cronistas. En un momento en que la historia aún no se dirigía a una audiencia internacional, el uso del latín conllevaba una recepción reducida y cualificada, vinculada a los propios letrados a cuyo grupo pertenecía el autor, y ello pudo favorecer la emergencia de una escritura audaz y excepcionalmente incisiva.

No fueron las de Pérez de Guzmán las únicas críticas sobre el trabajo de los cronistas. Hacia 1429, en su Traducción y glosas de la Eneida, Enrique de Villena arremete contra estos nuevos oficiales porque, a su juicio, carecen de la formación y de las capacidades para escribir una historia que responda a las necesidades de dar fama e inmortalidad a los hechos y a sus protagonistas. Las consideraciones de Villena parecen apoyarse directa o indirectamente en Cicerón (De oratore, II, 51-64), quien reclamaba del historiador que no fuera solo un narrador, sino también un embellecedor de los hechos:

En este paso, señor muy exçelente, devedes notar que poco vale a los grandes prínçipes e reyes fazer aseñalados e estrenuos fechos cuanto a la perpetuaçión de la fama si non ayan lengua enseñada que lo sepa dezir e por sçientíficas e dulçes palabras en scripto contar. E non encomendar, siquiere fiar, el fazer de las corónicas a escrivanos de cámara romançistas, segúnd en estas se faze partes ${ }^{47}$.

46 Ustaroz, Juan Francisco A. de y Dormer, Diego J. Progresos de la historia de Aragón y vida de sus cronistas. Zaragoza: Diputación Provincial, 1878, p. 637. En el mismo sentido podría interpretarse el caso posterior de Juan Ginés de Sepúlveda; véase CuART MONER, «La larga marcha hacia las historias de España en el siglo XVI», p. 72.

47 Villena, Enrique de. Obras completas, II: Traducción y glosas de la «Eneida»: libros I-III, ed. de Pedro M. Cátedra. Madrid: Turner, 1994, p. 24. Véase también su glosa a este pasaje: "Escrivanos de cámara etc. Fasta aquí fabló en general, mostrando cuánto cumplen los buenos fechos en corónicas poner por mano de personas entendidas. Aquí en speçial dize la mengua que d'esto avié en Castilla, encomendando el fazer de las corónicas a omes legos, ayunos de sçiençia, ignorantes de lengua latina, que non vieron otras istorias sinon las que ellos ordenavan. Por quanto en tiempo qu'el dicho don Enrique esto escrivió pocos sabién quién avié cargo de ordenar estas corónicas, salvo que por común fama se dezié avié d'ello cargo un escrivano de cámara que estava en Córdova e dávanle çient maravedís cada día e dezíenle el escrivano de las corónicas» (p. 47). Sobre este texto, Carr, Derek C. «Pérez de Guzmán and Villena: A Polemic on Historiography?». En Miletich, John S. (ed.). Hispanic Studies in Honor of Alan D. Deyermond: A North American Tribute. Madison: Hispanic Seminary of Medieval Studies, 1986, pp. 57-70. 
FRANCISCO BAUTISTA PÉREZ

HISTORIOGRAFÍA Y PODER AL FINAL DE LA EDAD MEDIA: EN TORNO

AL OFICIO DE CRONISTA

Aunque, en general, se ha dado crédito a las palabras de Villena, no debe perderse de vista el contexto polémico en el que figuran, en el cual cumplen una función de apología de su propio trabajo, y quizá están encaminadas a proponer su propia candidatura para el puesto de cronista.

De hecho, si tomamos estas críticas como referidas al individuo que ocupaba el cargo de cronista en 1429, esto es, a Álvar García de Santa María, lo cierto es que deben tomarse con cautela. Se conserva un manuscrito con materiales preparatorios de su obra, borradores y documentación, que aunque son solo un fragmento de lo que habría de ser su archivo de trabajo, nos permite acceder a sus métodos, los cuales se nos presentan como más modernos y eficaces que la consabida identificación de retórica e historia, popularizada por los humanistas italianos ${ }^{48}$. Así, sabemos que Álvar García dispuso de un itinerario regio para el relato que va de 1430 a 1434, o que elaboraba listados de cuestiones que necesitaba aclarar o resolver, y que entre otras cosas incluyen la búsqueda de documentación. Este tipo de materiales preparatorios, cuya conservación es sin duda excepcional, nos enfrenta a una tarea asumida con rigor, en la que el deseo de precisión y la investigación de la verdad no quedan como tópicos vacíos, y que lleva al desarrollo de una serie de protocolos de escritura sorprendentemente originales, que en absoluto se corresponden con la imagen trazada por Villena.

$\mathrm{Al}$ mismo tiempo, debe notarse que al situar el debate en el plano de la retórica, Villena abandona el problema de la relación entre la historia y el poder, o más bien privilegia una función panegírica de la escritura histórica, en tanto que estaría llamada a dejar constancia de las hazañas y grandes hechos. La historia se mira aquí en el espejo de la épica, y no es casual que estas consideraciones acompañen al texto romanceado de la Eneida. Aunque la creciente importancia de la retórica en la composición de los textos históricos se considera normalmente como un avance en el género, impulsado por el desarrollo del humanismo, no debe dejar de señalarse que la conjugación de estos dos elementos no dejó de ser un asunto polémico. Al criticar a Pedro del Corral y su Crónica sarracina, Pérez de Guzmán trataba de poner freno a la tentación de embellecer el pasado con la invención de sucesos sorprendentes o disparatados. Otro aspecto que podía resultar problemático fue el de la invención de los discursos, algo en lo que destacó Fernando del Pulgar. La introducción de largos parlamentos, en los que los actores de la historia debaten las razones o las enseñanzas de sus decisiones, era una marca inconfundible de la historiografía humanista, inspirada a su vez en modelos clásicos, y permitía desarrollar la capacidad de los textos como enseñanza para la vida o como monumento al servicio de los poderosos. De este modo, Pulgar ofrece sus discursos a ciertos aristócratas, sin importar que no exista ninguna relación con lo sucedido (véase su Letra XXXIII). Pero justamente tal rasgo fue criticado ya por Galíndez de Carvajal, que veía estos pasajes como «retórica vana» ${ }^{49}$. Como indicó

48 Bautista, "Álvar García de Santa María» y «La segunda parte de la Crónica de Juan II». Preparo en la actualidad una edición y estudio de este manuscrito.

49 Rosell (ed.), Crónicas de los reyes de Castilla, vol. III, p. 536. Más adelante, Jerónimo Zurita se mostró reticente también al uso de los discursos, frente a las insistencias de Antonio Agustín; véase GraftON, Anthony. What Was History? The Art of History in Early Modern Europe. Cambridge: University Press, 2007, pp. 232-233. 
FRANCISCO BAUTISTA PÉREZ

Arnaldo Momigliano, las relaciones entre retórica e historia, marcadas por la teorización latina, conforman uno de los problemas centrales de la historiografía bajomedieval y renacentista: «Ambiguity made rhetoric an art which could improve the historian's task and render it easier but which could also cripple it by distorting the truth" ${ }^{50}$.

En todo caso, la exigencia de una formación cultural distinguida, ligada a la necesidad de textos históricos en latín, fue en aumento a lo largo del siglo xv. En ciertos casos, los humanistas serán menos historiadores que traductores, como sucede con Antonio de Nebrija, nombrado cronista en 1509 y cuyas Decades son una versión parcial al latín de la obra de Pulgar. Ahora bien, esta creciente demanda de historias en latín, ligada a un contexto de difusión y recepción internacional de los textos, donde el uso de una lingua franca era imprescindible, creó a su vez nuevas polémicas en torno al cronista. El centro del debate no se sitúa aquí ya sobre la relación entre el cronista y el poder, o incluso sobre sus conocimientos literarios, sino sobre su situación dentro de la comunidad sobre la que escribe. En su Divinatio in scribenda historia, redactada en 1509, Nebrija reaccionaba duramente contra los italianos que pretendían escribir sobre la historia de España, ya que su envidia les impedía reconocer las virtudes y los éxitos de otros pueblos ${ }^{51}$. Se trata de una crítica frecuente, que había planteado ya Fabricio Gauberte de Vagad, cronista de Aragón, a fines del siglo Xv:

Los mismos ytalianos que siempre por invidia nos fueron tan enemigos que dissimularon quanto podieron, mas escondieron a mas no poder las excellencias de nuestra Hespaña ${ }^{52}$.

Así pues, en el ámbito de la historia escrita para su difusión internacional los textos se convierten en fuertemente apologéticos, como una defensa del propio reino frente a los ataques externos. Y ello tuvo como consecuencia el que la historiografía del siglo XvI sea en ocasiones más monolítica que la de la centuria anterior. Puede decirse que ese nuevo marco contribuyó a la creación de una historia oficial de forma más eficaz que las estrategias adoptadas por los monarcas a lo largo del siglo XV.

Una de las afirmaciones más conocidas del libro ¿Qué es la historia? de Edward H. Carr señalaba justamente la centralidad del estudio del historiador a la hora de interpretar los textos históricos: "Cuando llega a nuestras manos un libro de historia, nuestro primer interés debe ir al historiador, y no a los datos que contiene» ${ }^{53}$.

Esta suerte de hermenéutica de la sospecha, por la cual la valoración de los relatos debe suspenderse hasta conocer la posición de los autores, no es desde luego una creación de Carr, y tampoco de las artes historicae que proliferaron a lo largo de los siglos

50 Momigliano, Arnaldo. «The Rhetoric of History and the History of Rhetoric: On Hayden White's Tropes». En ÍD. Settimo contributo alla storia degli studi classici e del mondo antico. Roma: Edizioni di Storia e Letteratura, 1984, pp. 49-59 (cita en p. 59).

51 Bautista, Francisco. «Native historiography: Annius of Viterbo in Antonio de Nebrija». En EsTEVE, Cesc (ed.). Censorship and Historical Discourse in Early Modernity. Ashgate, en prensa.

52 TATE, Ensayos sobre la historiografía peninsular del siglo XV, p. 293, n. 26. No es casual que la primera voz en este sentido provenga de Aragón, ya que justamente Alfonso V había empleado exclusivamente historiadores italianos para relatar sus hechos y los de su padre.

53 CARR, Edward H. ¿Qué es la historia? Barcelona: Ariel, 2010, p. 91. 
FRANCISCO BAUTISTA PÉREZ

HISTORIOGRAFÍA Y PODER AL FINAL DE LA EDAD MEDIA: EN TORNO

AL OFICIO DE CRONISTA

XVI y XVII ${ }^{54}$. Como hemos visto, la discusión sobre el oficio del cronista gira directamente sobre los individuos que ocupaban o habían de ocupar ese cargo, y el mismo establecimiento de esta nueva figura burocrática a comienzos del siglo xv era una forma de reconocer implícitamente que, más allá de las ideas sobre la historia, la pregunta decisiva giraba en torno a quién había de escribir sobre el pasado. Pero, si el expediente para autorizar y controlar los textos históricos consistió en la creación de un nuevo oficio cortesano, surgieron al mismo tiempo dudas y respuestas sobre la posibilidad de que un individuo vigilado por el entorno del rey pudiera narrar con independencia los hechos pasados.

Todo este debate se agudizaba aún más al estar indisolublemente ligado a la historia reciente, a la tarea de referir sucesos contemporáneos, que trataban no solo de los reyes que gobernaban, sino también de grandes y nobles, deseosos de construir una imagen modélica de sí mismos y por tanto muy sensibles al relato de las crónicas. En este sentido, la discusión sobre la historia desbordaba ampliamente el ámbito de la retórica para ingresar en el de la política. Si es cierto que, como hemos visto, el cargo de cronista no impidió que algunos de los que lo detentaron tratasen de desarrollar su trabajo con cierta independencia, no lo es menos que la misma creación de este cargo ofrecía posibilidades de control que acabaron situando a los historiadores regios en una posición paradójica. Pues mientras que, por un lado, se encontraban en una situación privilegiada para testimoniar sobre su época y disponer de información de primera mano, lo que otorgaba a sus textos mayor solidez y precisión, por otro su vinculación al poder conllevaba una tentación o un claro intento de convertir a tales cronistas en portavoces de un partido o una opinión. Ahora bien, la conflictividad misma de la historia castellana del siglo xv dio lugar a una historiografía rica y polifónica, en la que no solo cada bando podía aspirar a tener su propio historiador, sino también en ocasiones estos pudieron encontrar espacio para construir sus propias perspectivas.

\section{REFERENCIAS BIBLIOGRÁFICAS}

Agnew, Michael. "Evangelista temporal: The Limits of Historiographical Disco<3urse in Juan de Flores's Royal Chronicle». En Gwara, Joseph J. (ed.). Juan de Flores: Four Studies. Londres: Department of Hispanic Studies, Queen Mary, University of London, 2005, pp. 11-47.

Bautista, Francisco. "Álvar García de Santa María y la escritura de la historia». En Cátedra, Pedro M. (dir.). Modelos intelectuales, nuevos textos y nuevos lectores en el siglo XV: contextos literarios, cortesanos y administrativos: primera entrega. Salamanca: Seminario de Estudios Medievales y Renacentistas, 2012 [2014], pp. 27-59.

Bautista, Francisco. «La segunda parte de la Crónica de Juan II: borradores y texto definitivo». Cahiers d'Études Hispaniques Médiévales, 2014, vol. XXXVII, pp. 105-138.

Bautista, Francisco. «Native historiography: Annius of Viterbo in Antonio de Nebrija». En EsTEve, Cesc (ed.). Censorship and Historical Discourse in Early Modernity. Ashgate, en prensa.

Bermejo Cabrero, José Luis. "Orígenes del oficio de cronista real». Hispania, 1980, vol. XL, pp. 395-409.

54 Grafton, What Was History?, p. 124. 
FRANCISCO BAUTISTA PÉREZ

HISTORIOGRAFÍA Y PODER AL FINAL DE LA EDAD MEDIA: EN TORNO

Bernáldez, Andrés. Memorias del reinado de los Reyes Católicos, ed. de Manuel Gómez-Moreno y Juan de M. Carriazo. Madrid: Real Academia de la Historia, 1962.

Cantera Burgos, Francisco. Álvar García de Santa María y su familia de conversos: historia de la Judería de Burgos y de sus conversos más egregios. Madrid: Instituto Arias Montano, CSIC, 1952.

Carr, Derek C. «Pérez de Guzmán and Villena: A Polemic on Historiography?». En Miletich, John S. (ed.). Hispanic Studies in Honor of Alan D. Deyermond: A North American Tribute. Madison: Hispanic Seminary of Medieval Studies, 1986, pp. 57-70.

CARr, Edward H. ¿Qué es la historia? Barcelona: Ariel, 2010.

Carriazo, Juan de Mata (ed.). Crónica de Juan II de Castilla. Madrid: Real Academia de la Historia, 1982.

Cátedra, Pedro M. «En los orígenes de las epistolas de relación». En Las «relaciones de sucesos» en España (1500-1750): Actas del Primer Coloquio Internacional (Alcalá de Henares, 8, 9 y 10 de junio de 1995). Paris: Publications de la Sorbonne; Alcalá de Henares: Servicio de Publicaciones de la Universidad de Alcalá, 1996, pp. 33-64.

Cuart Moner, Baltasar. «La larga marcha hacia las historias de España en el siglo Xvi». En GarCía CárCel, Ricardo (coord.). La construcción de las historias de España. Madrid: Marcial Pons, 2004, pp. 45-126 y 383-386.

Díaz de Games, Gutierre. El Victorial, ed. de Rafael Beltrán. Salamanca: Ediciones Universidad de Salamanca, 1997.

Enríquez del Castillo, Diego. Crónica de Enrique IV, ed. de Aureliano Sánchez Martín. Valladolid: Universidad, 1994.

Galíndez de Carvajal, Lorenzo. Prólogo a la Crónica de don Juan II. En Rosell, Cayetano (ed.). Crónicas de los reyes de Castilla. Madrid: Rivadeneyra, 1878, vol. II.

García, Michel (ed.). Crónica anónima de Enrique III de Castilla (1390-1391). Madrid: Marcial Pons, 2013.

García, Michel. "La crónica castellana en el siglo Xv». En Lucía Megías, José Manuel; Gracia Alonso, Paloma y Martín Daza, Carmen (eds.). Actas del II Congreso Internacional de la Asociación Hispánica de Literatura Medieval. Alcalá de Henares: Universidad de Alcalá, 1992, vol. I, pp. 53-70.

Giménez Soler, Andrés. Itinerario del rey Alfonso V de Aragón y I de Nápoles. Zaragoza: Mariano Escar, 1909.

Grafton, Anthony. What Was History? The Art of History in Early Modern Europe. Cambridge: University Press, 2007.

Guenée, Bernard. Histoire et culture historique dans l'Occident médiéval. Paris: Aubier, 1980.

Kagan, Richard. Clio and the Crown: The Politics of History in Medieval and Early Modern Spain. Baltimore: Johns Hopkins University Press, 2009.

KaGAN, Richard. Los cronistas y la Corona: la politica de la historia en España en las edades media y moderna. Madrid: Centro de Estudios Europa Hispánica, 2010.

López de Toro, José (ed. y trad.). Cuarta década de Alonso de Palencia. Madrid: Real Academia de la Historia, 1970-1974.

Momigliano, Arnaldo. "The Rhetoric of History and the History of Rhetoric: On Hayden White's Tropes». En Momigliano, Arnaldo. Settimo contributo alla storia degli studi classici e del mondo antico. Roma: Edizioni di Storia e Letteratura, 1984, pp. 49-59.

Morel-Fatio, Alfred. Historiographie de Charles-Quint: Première partie suivie des Mémoires de Charles-Quint. Paris: Honoré Champion, 1913.

Palencia, Alfonso de. Gesta Hispaniensia ex annalibus suorum dierum collecta, ed. de Brian Tate y Jeremy Lawrance. Madrid: Real Academia de la Historia, 1998-1999. 
FRANCISCO BAUTISTA PÉREZ

HISTORIOGRAFÍA Y PODER AL FINAL DE LA EDAD MEDIA: EN TORNO

AL OFICIO DE CRONISTA

Paz y Melia, Antonio. El cronista Alonso de Palencia. Madrid: The Hispanic Society of America, 1914.

Pérez de Guzmán, Fernán. Generaciones y semblanzas, ed. de Robert B. Tate. London: Tamesis, 1965.

Pontón, Gonzalo. «Fernando de Pulgar y la Crónica de los Reyes Católicos». En Pulgar, Fernando del. Crónica de los Reyes Católicos, ed. de Juan de Mata Carriazo. Granada: Universidad, 2008, vol. I, pp. lxxxv-lxxxvi.

Pulgar, Fernando del. Letras, ed. de Paola Elia. Pisa: Giardini, 1982.

Ruiz García, Elisa. «El poder de la escritura y la escritura del poder». En Nieto Soria, José Manuel (dir.). Orígenes de la monarquía hispánica: propaganda y legitimación (ca. 1400-1520). Madrid: Dykinson, 1999, pp. 275-313.

TATE, Robert B. «Alfonso de Palencia y los preceptos de la historiografía». En García DE LA CoNCHA, Víctor (ed.). Nebrija y la introducción del Renacimiento en España. Salamanca: Ediciones Universidad de Salamanca, 1983, pp. 37-51.

Tate, Robert B. «La historiografía del reinado de los Reyes Católicos». En Codoñer, Carmen y GonzÁlez Iglesias, Juan Antonio (eds.). Antonio de Nebrija: Edad Media y Renacimiento. Salamanca: Ediciones Universidad de Salamanca, 1994, pp. 17-28.

Tate, Robert B. "The Official Chronicler in the Fifteenth Century: A Brief Survey of Western Europe». Nottingham Medieval Studies, 1997, vol. XLI, pp. 157-185.

Tate, Robert B. Ensayos sobre la historiografía peninsular del siglo XV. Madrid: Gredos, 1970.

Ustaroz, Juan Francisco A. de y Dormer, Diego J. Progresos de la historia de Aragón y vida de sus cronistas. Zaragoza: Diputación Provincial, 1878.

Villena, Enrique de. Obras completas, II: Traducción y glosas de la «Eneida»: libros I-III, ed. de Pedro M. Cátedra. Madrid: Turner, 1994. 
